\title{
Behaviour of mycorrhizal fungi in fertilized forests
}

\author{
ESTERI OHENOJA
}

\begin{abstract}
OHENOJA, E. 1988: Behaviour of mycorrhizal fungi in fertilized forests. - Karstenia 28:27-30.

Reactions of fungi to application of fertilizers are discussed. The fruit body production of Lactarius rufus was measured by the "chronofrequency", dry weight and number of specimens, and the results are compared.
\end{abstract}

Esteri Ohenoja, Botanical Museum, University of Oulu, Linnanmaa, SF-90570 Oulu, Finland

The reaction of mycorrhizal fungi to application of fertilizers has received little attention, even in discussion of forest management and environmental factors in woodland.

In Finland, for example, fertilizing patterns and practices have been based on the growth of trees. Only after damage had been noted, chiefly in young plantations of conifers, was more extensive research devoted to the roots and mycorrhizae. Interest in the rhizosphere has also increased with the decline of forests in Central Europe.

Mycorrhizal fungi belong to a wide variety of species, however, which differ from each other in their reactions to $\mathrm{pH}$, chemical compounds, minerals, etc. They vary greatly genetically, so that the reactions of the same species to nutritional and environmental changes are not always the same. The situation is further complicated by the fact that two different organisms, plant and fungus, are involved, which differ greatly from each other in nutrition, chemical composition and physiology. The best way to study these questions is to undertake parallel studies in the field and laboratory.

The fertilizers applied to forest ecosystems and mires are often chemically heterogeneous and affect not only the tree, but also the chemistry of the soil and the physiology of the fungi. Fertilizers always cause a succession in the rhizosphere, which is dependent on many factors, such as the age of the trees, the tree species, time of treatment and concentration of fertilizers. The action of long-lasting fertilizers is also different from that of the rapidly dissolving ones.

\section{Function of mycorrhizal fungi}

The biomass of fungal hyphae in the soil is not very great when compared with the total organic mass. The proportion of fruit bodies of the whole mycelium is also small. Further, the nitrogen in fungal fruit bodies can form only ca. $0.1 \%$ of the total amount of nitrogen in the ecosystem. The nitrogen in the sporocarps is increased, however, by artificial application of nutrients, urine or other nitrogen fertilizers (Ohtonen 1984).

It seems that fungi do not represent a large store of nitrogen; their role is more that of transporters or processors. They are able to fix soluble compounds in fertilizers and they build insoluble substances such as chitin. In this way they create a new nutritional basis for organisms and increase the diversity of the stand. The role of mycorrhizal fungi is chiefly transport, while saprophytes mainly process organic matter.

\section{Quantity of fungal fruit bodies as indi-} cator of fertilization

The reaction of a fungus to application of nutrients varies with the site type and age of the forest. This could be seen, for instance, in the behaviour of Lactarius rufus on fertilized plots studied in three pine forests. This work is a part of a co-operative research project, LAVAME (Research on the effects of fertilization on the forest ecosystem), carried out in Finland (Ohenoja 1988). 
The first stand is very dry pine forest on sandy soil, the age of the trees being $60-80$ years. The pines in the second site are 80-100 years old and mixed with a few birches and spruces. The third site is the most mesic pine forest (with some birch), on morainic soil, the age of the pines being $60-80$ years.

Three methods were used to measure the occurrence and yield of the common mycorrhizal fungus Lactarius rufus (Fig. 1). The fruit bodies were counted and weighed during seven autumns on 96 experimental plots, one are in size. The "chronofrequency" was calculated from the number of times the species was found in autumn during the study period. The plots were usually checked twice a month.

In the first site the frequency of Lactarius rufus increased just after fertilization, but later, after 4-5 years of treatment, its fruit body production declined. The number of fruit bodies and the biomass varied more than the frequency, which may mean that the yields of mycelia changed. On UAB (urea, apatite and biotite) and UABM plots ( $\mathrm{M}=$ micronutrients), the biomass and number of fruit bodies did not decrease later as did the frequency, which may indicate increasing vigour of already existing mycelia and diminution of the number of mycelia. Laiho et al. (1987) found, however, that on these plots the short roots of pine had a significantly thinner mantle and the Hartig net penetrated less deep.

The older forest in the second site seemed to be very sensitive to fertilization. At least in the second phase, all the treatments reduced the production of Lactarius rufus, and other mycorrhizal fungi, as well. In the most mesic pine forest, both the frequency and yields of Lactarius rufus increased on urea and nitroform plots, but decreased on the plots receiving other fertilizers.

\section{Discussion}

The mycorrhizal fungus species usually occupy only a restricted area in the rhizosphere, so that their occurrence in a stand is scattered, and their reactions can be measured fairly well with the help of frequencies. But if competition between species is also to be observed, quantitative measurements may give a better result. Hora (1959) suggested that fungi show interspecific adaptation and competiton for the nutrient supply. According to him, two vigorous species should not be regarded as competitors, e.g. Lactarius rufus and Paxillus involutus, which were common in pine plantations. In northern forests Paxillus involutus does not thrive very well with pine
(Laiho 1970), but does better with birch, and we cannot compare it with Lactarius rufus. In pine forests, Laccaria bicolor benefits from fertilizer and could compete with Lactarius rufus. In all the forests studied, the Cortinarius species have been sensitive to fertilization, and their frequencies and yields have diminished (Ohenoja 1988).

When the amount of nitrogen increases in the forest ecosystem, but there are no extra carbon sources, mycorrhizal formation may cease (Meyer 1988). This must be reflected in the production of sporocarps. A high nitrogen level increases the growth of the host of the fungus, and this can exhaust certain nutrients, such as magnesium and potassium, which the fungus cannot obtain in sufficient quantity from the soil.

The $\mathrm{pH}$ is also an important regulator of the fungus flora and production. Fertilization changes the reaction of the humus, which may affect some fungi more than the fertilizer itself, the $\mathrm{pH}$ amplitudes and optima setting limits to their production. Urea raises the $\mathrm{pH}$ somewhat in forest soil, but the most notable increase occurs on the plots treated with $\mathrm{UAB}$ and UABM. When the soil becomes less acid, the decomposing bacteria increase releasing nitrogen and other nutrients from the litter, but also using nitrogen and thus competing with fungi and other organisms. In stands on poor soil, increasing acidity can raise the fungus production (Wästerlund 1982). Species adapted to low $\mathrm{pH}$ (e.g. Suillus bovinus) can strengthen their position and compete for space in the rhizosphere.

Sagara (1975) classified fungus species as ureobionts, ureophiles, ureoxenes and ureophobes. Our study forests contained only saprophytic ureobionts (Ohenoja 1988). When ureophilous species are considered, account must be taken of the role of time and the concentration of fertilizer. During the first two or three seasons after treatment, species showing ureophilous features were, e.g. Paxillus involutus, Laccaria bicolor, Lactarius rufus and Hebeloma species. But in the second phase, the fruit body production sank in many cases under the control level. After that only Paxillus involutus and Laccaria bicolor could still be considered ureophilous. Hebeloma species, which in the study forests chiefly became more productive on $U A B$ and UABM plots, form mycorrhizae with birch. In this case, the effect of fertilization is more secondary and may thus occur through changes in $\mathrm{pH}$. If cessation of production of fruit bodies is a sign of ureophobism, this was especially noticeable in the Cortinarii. But it must be remembered that many secondary phenomena, such as changes in the vegetation, $\mathrm{pH}$, soil chemistry and nutrient equilibrium may also play a role. 

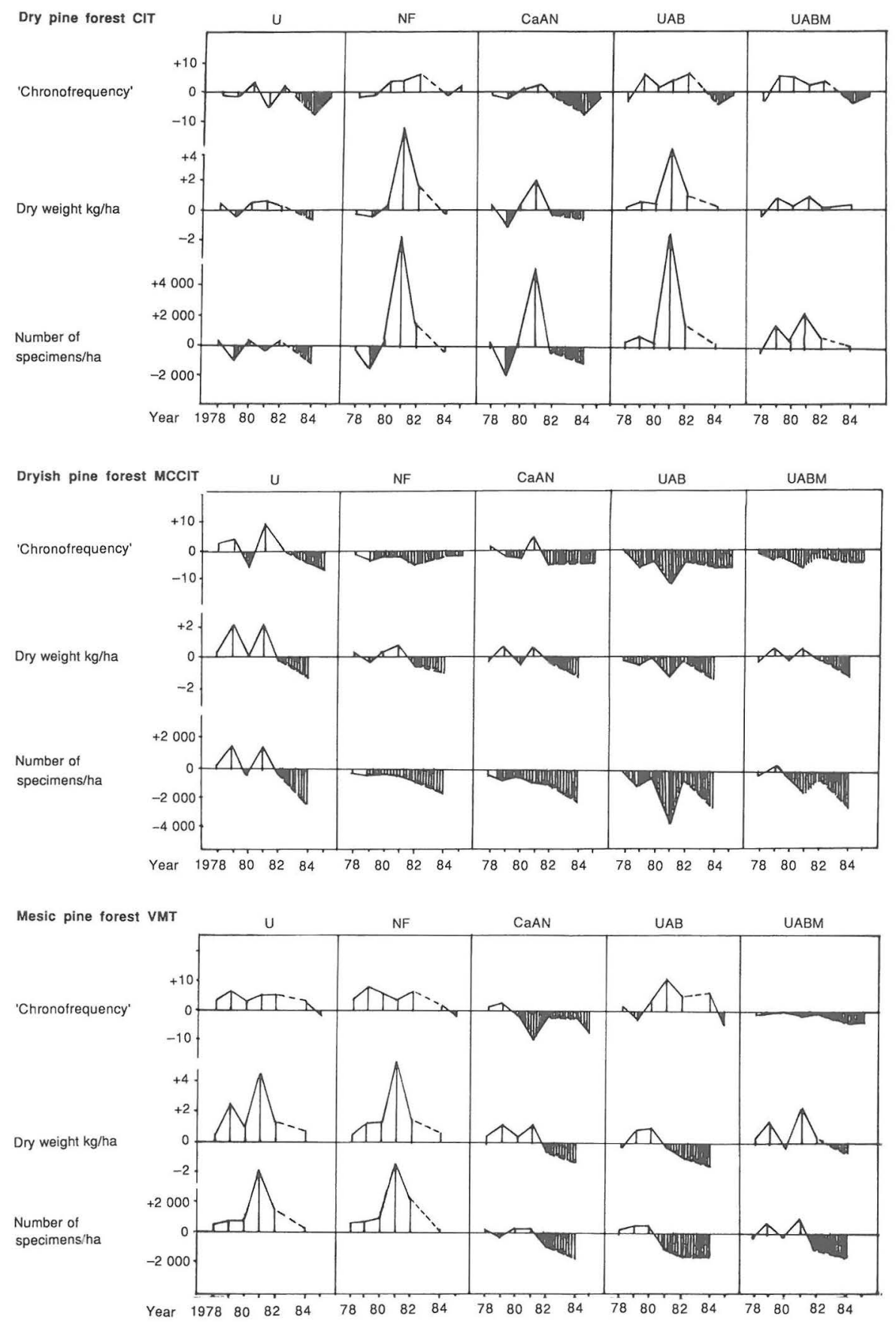

Fig. 1. Deviations of (I) the 'chronofrequency', (II) the dry weight of fruit bodies, and of (III) the number of the specimens of Lactarius rufus from controls (0-level) on fertilized plots in a dry, dryish and mesic pine forest at Pudasjärvi, N. Finland. Fertilizers were applicated in spring 1979. $\mathrm{U}=$ urea, $\mathrm{NF}=$ nitroform, $\mathrm{CaAN}=$ calcium ammonium nitrate, $\mathrm{UAB}=$ urea + apatite + biotite, $\mathrm{UABM}=$ urea + apatite + biotite + micronutrients. 


\section{References}

Hora, F.B. 1959: Quantitative experiments on toadstool production in woods. - Trans. Brit. Mycol. Soc. 42:1-14.

Laiho, O. 1970: Paxillus involutus as a mycorrhizal symbiont of forest trees. - Acta Forest. Fennica 106:1-72.

Laiho, O., Sarjala, T., Hyvärinen, R. \& Rautiainen, L. 1987: Lannoituksen vaikutus männikön mykoritsoihin. (Summary: Effect of fertilization on mycorrhizae in pine stands.) - Folia Forest. 699:1-22.

Meyer, F.H.: Fungi and decline of forests. - Atti del Centro Studi per la Flora Mediterranea 7 (in press).

Ohenoja, E.: Forest fertilization and fruiting body production in fungi. - Atti del Centro Studi per la Flora Mediterranea 7 (in press).

Ohtonen, R. 1984: The effect of forest fertilization on the nitrogen content of the fruit-bodies of two mycorrhizal fungi, Lactarius rufus and Suillus variegatus. - Ann. Bot. Fennici 23:189-203.

Sagara, N. 1975: Ammonia fungi - A chemoecological grouping of terrestrial fungi. - Contr. Biol. Labor. Kyoto Univ. 24:205-290.

Accepted for publication

on 20 September 1988 